\title{
Nintendo Wii training on postural balance and mobility rehabilitation of adults with Parkinson's disease: a systematic review
}

\author{
Treinamento com Nintendo Wii na reabilitação do \\ equilíbrio postural e mobilidade de indivíduos com \\ Doença de Parkinson: uma revisão sistemática
}

\author{
Daniel Dominguez Ferraz ${ }^{[\mathrm{a}]}$, Karen Trippo ${ }^{[\mathrm{a}]}$, Adriana Dominguez ${ }^{[\mathrm{b}]}$, Adriana Santos ${ }^{[\mathrm{a}]}$, \\ Jamary Oliveira Filho ${ }^{[]^{*}}$
}

[a] Universidade Federal da Bahia (UFBA), Salvador, BA, Brazil

[b] King's College Hospital, Denmark Hill, London, United Kingdom

\section{Abstract}

Introduction: Postural instability affects balance control in Parkinson disease (PD) patients and increases the particular risk of falling compared with healthy older adults. Video games with not immersive virtual reality have been used in neurological disorders rehabilitation process. Objective: To evaluate the effectiveness of the video game console Nintendo Wii (NW) on postural balance and mobility treatment of adults with PD in Hoehn and Yahr stages I to III. Methods: The following databases were searched electronically on MEDLINE, Cochrane Library, PEDro, CAPES Periodic, BIREME, and LILACS databases. The search period for this review was January 2010 to June 2016. The assessment of methodological quality was performed using the PEDro Scale as reference. Results: 12 original studies were selected, but only 3 were randomized controlled trials (RCTs). Conclusion: Some of the studies analysed suggest that NW can provide improvement in balance and mobility of adults with PD. These benefits should be interpreted with

\footnotetext{
DDF: Doctoral student, e-mail: danieldf@ufba.br

KT: Doctoral student, e-mail: karentrippo@superig.com.br

AD: BS, e-mail: adriana.dominguez@nhs.net

AS: PhD, e-mail: saraiva.fisio@gmail.com

JOF: PhD, e-mail: jamary@mail.harvard.edu
} 
caution because of the low methodological quality of the included trials, and the lack of common assessment of treatment effects. There is little evidence to ensure the effectiveness and support the inclusion of the treatment with NW of patients with PD.

Keywords: Parkinson Disease. Virtual Reality Exposure Therapy. Video Games. Rehabilitation.

\section{Resumo}

Introdução: A instabilidade Postural altera o controle do equilíbrio em pacientes com Doença de Parkinson (DP) e diminui o risco de quedas quando comparado a idosos saudáveis. Vídeo games com realidade virtual não imersiva tem sido utilizados no processo de reabilitação de desordens neurológicas. Objetivo: Avaliar a eficácia do videogame Nintendo Wii (NW) no tratamento do equilíbrio postural e mobilidade de pacientes adultos com DP em estágios I a III da escala de Hoehn \& Yahr. Métodos: As seguintes bases de dados foram pesquisadas eletronicamente no período de março e junho 2016: MEDLINE, Biblioteca Cochrane, PEDro, Periódico CAPES, BIREME e bases de dados Lilacs, publicados até 03 de julho de 2016. A avaliação da qualidade metodológica foi realizada utilizando a Escala PEDro como referência. Resultados: 12 estudos originais foram selecionados, mas apenas 3 eram ensaios clínicos randomizados (ECRs). Conclusão: Alguns dos estudos analisados sugerem que o NW pode proporcionar melhora no equilíbrio e na mobilidade de adultos com DP. Estes benefícios devem ser interpretados com cautela por causa da baixa qualidade metodológica dos estudos incluídos e da falta de avaliação comum dos efeitos do tratamento. Há pouca evidência para garantir a eficácia e apoiar a inclusão do tratamento com NW em pacientes com DP.

Palavras-chave: Doença de Parkinson. Terapia de Exposição à Realidade Virtual. Jogos de Vídeo. Reabilitação.

\section{Introduction}

The health service improvements promote the world ageing. It is expected that the number of elderly people will increase from 605 million to 2 billion between 2000 and 2050 [1]. This increasing is a phenomenon already quite evident in developed countries. Thus, the chronic diseases are actually the most significant health problem in the world [2]. Among the chronic neurodegenerative disorders, PD is the second most prevalent [3], affecting about 1,5 to $2 \%$ of the elderly population [4].

PD is a subcortical injury with loss of dopaminergic neurons in the mid-brain substantia nigra [5]. Individuals with PD present classical neurological symptoms as resting tremor, rigidity and bradykinesia [6]. These symptoms progress limiting the walking ability [7], physical endurance [8], balance and functional independence for basic activities of daily living [9].

These limitations can influence PD patients to present a lower level of physical activity comparing with healthy controls [10]. A good level of physical endurance can contribute to a slower disease progression [11]. It seems that PD participants in an exercise program have a better perception of quality of life and a superior walking ability, postural balance, strength level, flexibility and fitness capacity, compared to physically inactive patients [11]. However to improve the mobility of the PD subjects, the training should be specific to treat balance and gait control [12].

Postural instability affects balance control in PD, increasing the particular risk of falling compared with healthy older adults [13]. Approximately 50\% of persons with PD fall [14] and around one third of falls are caused by an unstable posture [15].

The aging disorders added to chronic symptomatology of PD make the elderly patient dependent on physical exercise throughout life. In this way, the exercise program should motivate the patient and mitigate disease progression. So the video game with not immersive virtual reality can be an exercise mode for patients with PD, because it brings the possibility of moving up to play.

Video game with not immersive virtual reality is a form of multisensory exercises that has been used in neurological disorders rehabilitation process [16]. One of the relatively recent resources available for 
virtual reality is the video game NW. The NW can promote interactive games using a balance board system, named Wii Fit video game that tracks changes in the centre of pressure during exercise performance. These characteristics indicate that the Wii Fit may be a promising platform for training postural balance of patients with PD.

NW was the first video game used to improve postural balance and mobility in patients with $\mathrm{PD}$ and a recent publication has been increasing in this area in the last three years. The purpose of this systematic review was to assess the effectiveness of treatment with NW in postural balance and mobility of adults with PD.

\section{Methods}

This systematic review followed PRISMA (Preferred Reporting Items for Systematic reviews and Meta-Analysis) protocol guidelines [17]. The following databases were searched electronically in March and updated in June 2016: Medical Literature Analysis and Retrieval System Online (MEDLINE/ PubMed), Cochrane Register of Controlled Trials (CENTRAL CCTR/Cochrane Library), Physiotherapy Evidence Database (PEDro), CAPES Periodic, Regional Library of Medicine (BIREME), Latin American and Caribbean Literature on Health Sciences (LILACS).

The relevant studies were obtained by crossing the descriptors in English, using the Boolean operators "AND" and "OR". The search in databases was performed using MeSH (Medical Subject Headings) and DECS (Health Sciences Descriptors): "virtual reality exposure therapy", "video games", "postural balance" and "Parkinson disease". The words "Wii", "Nintendo Wii" and "virtual reality" were also kept in the research strategy to avoid missing relevant articles. The research strategy used in electronic databases is shown in Table 1.

Table 1 - Strategy for electronic databases survey

\begin{tabular}{|c|c|}
\hline Electronic databases & Key words (DECS/MeSH) \\
\hline MEDLINE/PubMed & $\begin{array}{l}\text { ((("Virtual Reality Exposure Therapy"[Mesh]) OR "Video Games"[Mesh]) AND "Postural Balance"[Mesh]) AND } \\
\text { "Parkinson Disease"[Mesh] }\end{array}$ \\
\hline Cochrane Library & $\begin{array}{l}\text { Parkinson Disease AND Video Games; Parkinson Disease AND Wii; Parkinson Disease AND Virtual Reality; } \\
\text { Parkinson Disease AND virtual reality exposure therapy. }\end{array}$ \\
\hline PEDro & $\begin{array}{l}\text { Parkinson Disease AND Video Games; Parkinson Disease AND Wii; Parkinson Disease AND Virtual Reality; } \\
\text { Parkinson Disease AND virtual reality exposure therapy. }\end{array}$ \\
\hline CAPES Periodic & $\begin{array}{l}\text { Parkinson Disease AND Video Games AND Postural Balance; Parkinson Disease AND Wii AND Postural } \\
\text { Balance; Parkinson Disease AND Virtual Reality AND Postural Balance; Parkinson Disease AND virtual reality } \\
\text { exposure therapy. }\end{array}$ \\
\hline BIREME & $\begin{array}{l}\text { Parkinson Disease AND Video Games; Parkinson Disease AND Wii; Parkinson Disease AND Virtual Reality; } \\
\text { Parkinson Disease AND virtual reality exposure therapy. }\end{array}$ \\
\hline LILACS & $\begin{array}{l}\text { Parkinson Disease AND Video Games; Parkinson Disease AND Wii; Parkinson Disease AND Virtual Reality; } \\
\text { Parkinson Disease AND virtual reality exposure therapy. }\end{array}$ \\
\hline
\end{tabular}

Note: DECS: Health Sciences Descriptors; MeSH: Medical Subject Headings; MEDLINE: Medical Literature Analysis and Retrieval System Online; PEDro: Physiotherapy Evidence Database; CAPES: Improving Coordination of Higher Education Personnel; BIREME: Latin American and Caribbean Center on Health Sciences Information LILACS: Index of scientific and technical literature of Latin America and the Caribbean.

Selection of Studies and Study Quality

The assessment of methodological quality of the randomized clinical trials was conducted by the PEDro Scale based on the Delphi list [18]. Two reviewers, using the same search strategy, identified and selected independently the titles and abstracts of all primary studies. Any discrepancy between the results was resolved in a consensus meeting. The full text of all chosen studies was obtained to assess whether it fulfilled the per-established inclusion criteria. 
Inclusion Criteria

Studies that met the following inclusion criteria were included: (a) RCTs; (b) Studies that performed comparative analysis between pretreatment and post-treatment period; (c) caseseries and case studies. All articles reported a NW based intervention for balance postural or mobility of people with PD and over 50 years old. All papers were full scientific and written in English, Portuguese or Spanish. The literature search was limited to the dates January 1, 2010, to June 3, 2016.

\section{Exclusion Criteria}

Conference posters and abstracts were excluded. Review articles, meta-analysis, and editorials were also excluded, as well as published studies on the clinical trial protocol layout as they do not have final data to be analysed in this systematic review.

\section{Data Extraction}

An adaptation of Cochrane Collaboration Checklist [19] for data extraction was developed by the authors. The form was made of fields to be filled by a reviewer in the following order: (a) study identification (main author's name, year, published magazine, and country); (b) study method (type of study, blinding, and secret allocation); (c) target population aspects (age, sex, and time of injury); (d) aspects of the intervention performed (sample size, type of games used, presence of supervision, frequency, session length, the place where the treatment was performed and follow-up); (e) studied outcomes; and (f) presented results.

\section{Results}

A total of 185 articles were identified using the strategy applied in electronic databases survey (Figure 1). All non-experimental studies were excluded. After reading the titles and abstracts by two reviewers independently, articles were excluded for not having relation with the subject studied. The reviewers in common selected 18 potentially relevant articles, and in a consensus meeting, five separate articles were included, totalizing 23 articles. From the 23 studies selected, 12 met the inclusion criteria after full reading of the articles.

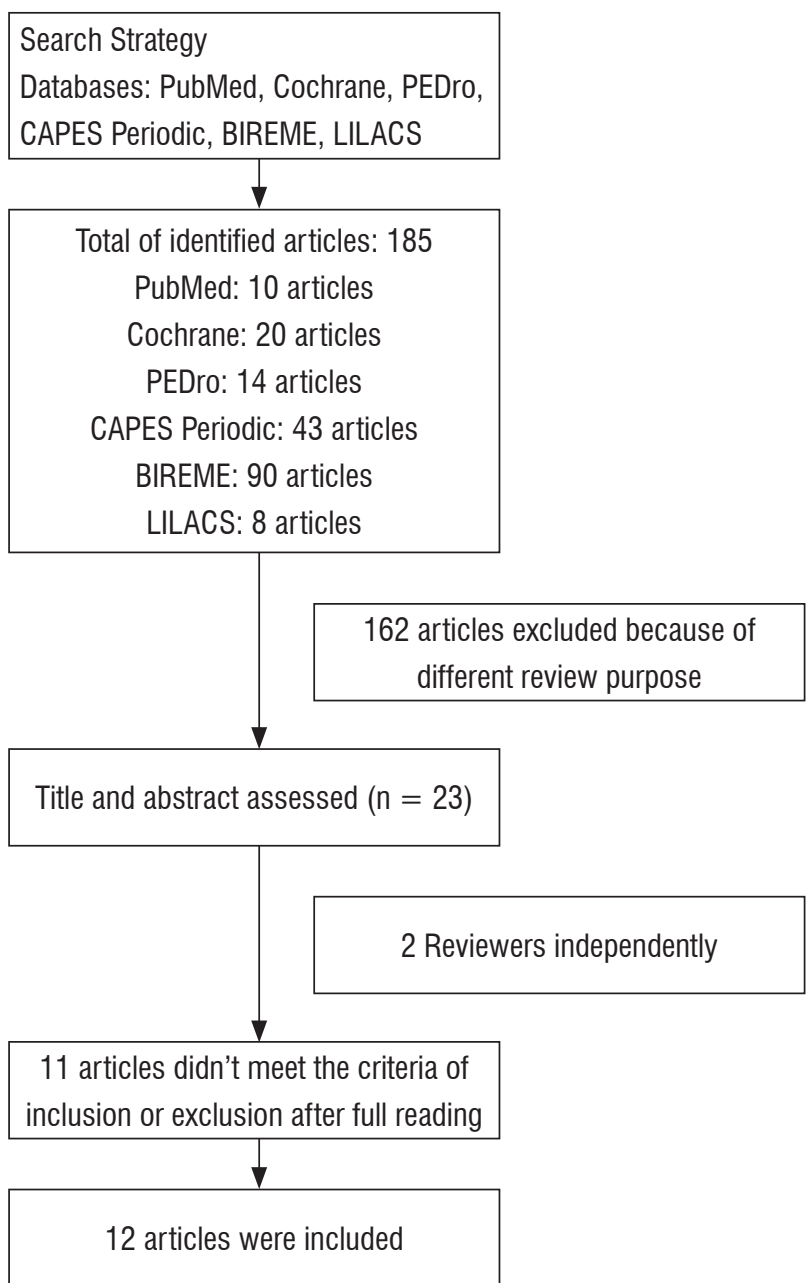

Figure $\mathbf{1}$ - Flowchart of the survey in electronic databases.

As a methodological quality of the randomized clinical trials, the score on the PEDro scale ranged from 4 to 7 . Table 2 shows the scores and the items included in the scale for each study. From the studies, all of them were included in similar groups (experimental and control) and presented randomization of subjects. Two studies had blinding of assessors, but none of the studies carried out the blinding of participants and therapists who conducted the sessions. 
Table 2 - Methodological quality of the study by PEDro scale

\begin{tabular}{|c|c|c|c|c|c|c|c|c|c|c|c|c|}
\hline Authors & $1 *$ & 2 & 3 & 4 & 5 & 6 & 7 & 8 & 9 & 10 & 11 & Score \\
\hline Pompeu et al, $2012^{20}$ & & $x$ & & $x$ & & & $x$ & & & $x$ & $x$ & 5 \\
\hline Liao et al, $2015^{21}$ & $x$ & $x$ & $x$ & $x$ & & & $x$ & $x$ & & $x$ & $x$ & 7 \\
\hline Lee, Lee and Song, $2015^{22}$ & & $x$ & & $x$ & & & & & & $x$ & $x$ & 4 \\
\hline
\end{tabular}

Note: The Pedro scale scores 10 items: 1 = eligibility criteria ( ${ }^{*}$ not accounted); $2=$ random allocation; $3=$ concealed allocation; $4=$ baseline comparability; $5=$ participants blinded; $6=$ therapists blinded; $7=$ assessors blinded; $8=$ follow-up in $>85 \%$ of participants; 9 $=$ all participants receive treatment or control condition; $10=$ between group analysis; $11=$ accuracy measures.

The NW

The NW presents as an easily gradable and standardized rehabilitation training modality that is safe and provides patients with access to activities that may not be available otherwise [23]. This popular technological tool is cheaper and much more accessible than several programs applied in clinics and research laboratories. The NW offers a rich environment of sensory cues combining visual, auditory and proprioceptive feedback training as a direct application of VR. These stimuli may provide patients affected by PD more ways to enhance attention and focus on the required moves in the game and make them more explicit by using the motor, oculomotor, cerebellar and limbic loops [24]. The games demand cognitive skills like attention to solve the tasks, working memory and performance management [20]. Players are also motivated by the results obtained in the game, which encourage them to gain points and beat their scores [25].

The possibility of training in a home setting is another feasible advantage [26]. Zalecki et al. [26] demonstrated that patients with PD reported satisfaction, enjoyment and comfort during the home NW sessions and could foresee a need for such training in the future. However, for best results the games must be carried out under the supervision of a physiotherapist. This professional should participate actively in the training session, assisting the player about the necessary movements for a good game performance by somatosensorial stimulation, postural corrections and verbal instructions [20].

Studies have shown that PD-affected people require more attentional resources to balance control [27]. In this way, challenge training is recommended to improve balance. The NW exercises can be a highly challenging training, because it induces a division of attention among the performance of virtual tasks, the body movements and the postural responses [28].

The games

The most used NW games to improve balance in people suffering from PD were: Penguin Slide, Table Tilt, Balance Bubble, Ski Slalom, Ski Jump, Single Leg Extension, Torso Twist, Tilt City and Soccer Heading. Some games were used specifically for static balance (Single Leg Extension and Torso Twist) and others for dynamic balance (Table Tilt, Tilt City, Soccer Heading and Penguin Slide) [20]. However two studies have innovated using NW dance games [29] and Wii Sports [30] to improve balance for elderly adults with PD.

There is no consensus about how many games per session are recommended. The duration of NW training raged between 4 to 8 weeks, and the patients played individually for approximately 1 hour, two or three times per week.

According to Negrini et al. [31] a program of 30 minutes for 2 days per week during 5 weeks (10 total training sessions) is enough to reveal significant differences between the pre-treatment with post-treatment.

The patients

No patients need to have prior experience with the NW games, but not everyone can train with the game. Only a group of patients is able to be trained with NW exercises. The patients need to have a good visual and auditory acuity, basic level of education (5 to 15 years), no other neurological or orthopaedic diseases, dementia (assessed by the Mini Mental 
State Examination, cut-off 23 - 24 points) or depression (according to the Geriatric Depression Scale, cut-off 6 points) and also an independent walking ability.

The assessments

Many balance assessment were applied, but the Balance Berg Scale (BBS) was the most used.
Others tools were used to evaluate balance and mobility like Force Platform [25], Timed Up and Go test (TUG) [23, 32, 33], Dynamic Gait Index (34), Sharpened Romberg Test [34], Tinnet's Performance Oriented Mobility Assessment (POMA) [26], Balance Evaluation Systems Test [34], Movement Velocity [35] and Sensory Organization Test [35]. Table 3 summarizes the variables studied and the results of the 11 experimental studies eligible for this systematic review.

Table 3 - Characteristics of the variables and the outcome of treatment with Nintendo Wii in experimental studies included in this review

\begin{tabular}{|c|c|c|c|}
\hline Author/year/study & $\begin{array}{l}\text { Sample / Age mean / } \\
\text { Level of PD }\end{array}$ & Instruments of evaluation & Results / Conclusions \\
\hline $\begin{array}{l}\text { Zettergren et al, } 2011 \\
\text { [32] (Case Study) }\end{array}$ & $\begin{array}{l}n=1 \\
69 \text { years }\end{array}$ & $\begin{array}{l}\text { TUG } \\
\text { BERG } \\
\text { Self selected gait speed } \\
\text { Fall history } \\
\text { GDS }\end{array}$ & $\begin{array}{l}\text { After } 8 \text { weeks, the subject's BBS score and the gait } \\
\text { speed have increased, the TUG decreased and and } \\
\text { GDS scores remained unchanged. The Nintendo Wii } \\
\text { Fit may be a viable alternative to independent exercise } \\
\text { programs for people diagnosed with idiopathic PD. }\end{array}$ \\
\hline $\begin{array}{l}\text { Esculier et al, } 2012 \text { [25] } \\
\text { (Clinical Trial) }\end{array}$ & $\begin{array}{l}n=20 \\
n=9 \text { Health people } \\
64 \text { years } \\
n=11 \text { People with PD } \\
62 \text { years } \\
18.4-\text { UPDRS }\end{array}$ & $\begin{array}{l}\text { STST } \\
\text { TUG } \\
\text { POMA } \\
\text { 10-m walk test } \\
\text { CBM } \\
\text { ABC } \\
\text { Unipodal stance duration } \\
\text { Force platform }\end{array}$ & $\begin{array}{l}\text { The PD group significantly improved their results in } \\
\text { TUG ( } p<0.04) \text {, STST }(p<0,01) \text {, unipodal stance } \\
(p<0.05), 10-m \text { walk test }(p<0.001) \text {, CBM } \\
(p<0.001) \text {, POMA ( } p<0.05) \text { and force platform } \\
\text { after the training programme. The healthy subjects } \\
\text { group significantly improved in TUG ( } p<0.001) \text {, } \\
\text { STST ( } p<0.01) \text {, unipodal stance and CBM ( } p \\
<0.02) \text {. This study suggests that a home-based } \\
\text { balance programme using Wii Fit could improve static } \\
\text { and dynamic balance, mobility and functional abilities } \\
\text { of people with PD. }\end{array}$ \\
\hline $\begin{array}{l}\text { Pompeu et al, } 2012 \text { [20] } \\
\text { (Randomised clinical } \\
\text { trial) }\end{array}$ & $\begin{array}{l}n=32 \\
67 \text { years } \\
\text { Hoehn and Yahr stages } 1 \\
\text { and } 2\end{array}$ & $\begin{array}{l}\text { UPDRS-II } \\
\text { BERG } \\
\text { Unipedal Stance Test } \\
\text { Montreal Cognitive } \\
\text { Assessment }\end{array}$ & $\begin{array}{l}\text { Both groups showed a significant improvement } \\
(\mathrm{p}<0.05) \text { on the UPDRS-II, BBS, Unipedal Stance } \\
\text { Test and Montreal Cognitive Assessment after } \\
\text { training that was maintained at follow-up. Wii Fit } \\
\text { could be used as a new tool in association with } \\
\text { physical therapy in order to improve motivation, and } \\
\text { consequently adherence. }\end{array}$ \\
\hline $\begin{array}{l}\text { Loureiro et al, } 2012 \text { [33] } \\
\text { (Quasi-experimental } \\
\text { design) }\end{array}$ & $\begin{array}{l}n=6 \\
65 \text { years } \\
\text { Hoehn and Yahr stages } 2 \\
\text { and } 3\end{array}$ & $\begin{array}{l}\text { Borg's Scale } \\
\text { BERG } \\
\text { Notthingham's Scale } \\
\text { TUG } \\
\text { Functional Reach }\end{array}$ & $\begin{array}{l}\text { Statistically significant differences were found in the } \\
\text { following tests: Borg's Scale and BERG. The TUG and } \\
\text { Notthingham's Scale was not statistically significant } \\
\text { when comparing the initial and final values. It is } \\
\text { believed that exercises with virtual reality therapy can } \\
\text { be a useful tool to improve the balance in PD patients. }\end{array}$ \\
\hline $\begin{array}{l}\text { Mhatre et al, } 2013 \text { [34] } \\
\text { (Quasi-experimental } \\
\text { design) }\end{array}$ & $\begin{array}{l}n=10 \\
67 \text { years } \\
\text { Hoehn and Yahr stages 2,5 } \\
\text { and } 3\end{array}$ & $\begin{array}{l}\text { BERG } \\
\text { DGI } \\
\text { Sharpened Romberg with } \\
\text { eyes open and closed } \\
\text { Postural sway using the Wii } \\
\text { balance board } \\
\text { ABC } \\
\text { GDS }\end{array}$ & $\begin{array}{l}\text { The BBS }(p<0.016) \text { and DGI }(p<0.004) \text { improved } \\
\text { significantly, as did postural sway measured } \\
\text { with the balance board. The Sharpened Romberg } \\
\text { improvements significance only for eyes open } \\
\text { ( } p<0.049) \text {. There were no significant changes } \\
\text { on patient ratings for the Activities-specific Balance } \\
\text { Confidence. An exercise training class by using the } \\
\text { Wii Fit balance board improved selective measures } \\
\text { of balance and gait ( } p<0.035 \text { ) in adults with PD. } \\
\text { However, no significant changes were seen in mood } \\
\text { or confidence regarding balance. }\end{array}$ \\
\hline
\end{tabular}


(Conclusion)

Table 3 - Characteristics of the variables and the outcome of treatment with Nintendo Wii in experimental studies included in this review

\begin{tabular}{|c|c|c|c|}
\hline Author/year/study & $\begin{array}{l}\text { Sample / Age mean / } \\
\text { Level of PD }\end{array}$ & Instruments of evaluation & Results / Conclusions \\
\hline $\begin{array}{l}\text { Herz et al, } 2013 \text { [23] } \\
\text { (Quasi-experimental } \\
\text { design) }\end{array}$ & $\begin{array}{l}\mathrm{n}=20 \\
67 \text { years } \\
\text { Hoehn \& Yahr Stage } 2\end{array}$ & $\begin{array}{l}\text { 9-hole peg test } \\
\text { POMA } \\
\text { Purdue Pegboard Test } \\
\text { Timed tapping test } \\
\text { TUG } \\
\text { Hamilton Depression Scale } \\
\text { Nottingham Extended } \\
\text { Activities of Daily Living Test } \\
\text { PDQ-39 } \\
\text { NEADL } \\
\text { UPDRS }\end{array}$ & $\begin{array}{l}\text { There was a significant improvement in the right-sided } \\
\text { 9-hole peg test score and TUG score between } \\
\text { pre- and post-intervention. This study demonstrates } \\
\text { that the Nintendo Wii gaming system can be an } \\
\text { effective treatment modality for patients with PD. } \\
\text { However further studies are needed to determine if } \\
\text { there are long-term benefits of this therapy in PD. }\end{array}$ \\
\hline $\begin{array}{l}\text { Zalecki et al, } 2013 \text { [26] } \\
\text { (Quasi-experimental } \\
\text { design) }\end{array}$ & $\begin{array}{l}n=24 \\
69 \text { years }\end{array}$ & $\begin{array}{l}\text { BERG } \\
\text { POMA } \\
\text { TUG } \\
\text { Sit-to-stand test } \\
\text { 10-Meter Walk test } \\
\text { ABC }\end{array}$ & $\begin{array}{l}\text { There was a significantly improvement in BERG } \\
(p<0.0001) \text {, POMA }(p<0.001) \text {, TUG }(p<0.05) \text {, } \\
\text { Sit-to-stand test }(p<0,05), 10 \text {-Meter Walk test } \\
(p<0.05) \text { and Activities-specific Balance Confidence } \\
\text { scale }(p<0.003) \text { at the end of the programme. }\end{array}$ \\
\hline $\begin{array}{l}\text { da Silva et al, } 2013 \text { [30] } \\
\text { (Quasi-experimental } \\
\text { design) }\end{array}$ & $n=6$ & $\begin{array}{l}\text { Goniometry } \\
\text { Trunk Mobility Scale } \\
\text { BERG } \\
\text { PDQ-39 }\end{array}$ & $\begin{array}{l}\text { It was observed that treatment using Wii Sports } \\
\left.\text { (Nintendo Wii }{ }^{\top}\right) \text { games was able to increase, range } \\
\text { of movement }(p<0.03) \text {, trunk mobility }(p<0,003) \text {, } \\
\text { balance }(p<0.02) \text { and quality of life of individuals } \\
\text { with PD }(p<0.03) \text {. }\end{array}$ \\
\hline $\begin{array}{l}\text { Liao et al, } 2015[36] \\
\text { (Randomized controlled } \\
\text { trial) }\end{array}$ & $\begin{array}{l}n=36 \\
\text { Hoehn and Yahr score } \\
\text { ranging } 1 \text { to } 3 \\
\text { Wii Fit exercise }(n=12) \\
\text { Traditional exercise }(n=12) \\
\text { No structured exercise } \\
\text { program }(n=12)\end{array}$ & $\begin{array}{l}\text { Obstacle crossing } \\
\text { performance Dynamic } \\
\text { balance } \\
\text { SOT } \\
\text { PDQ-39 } \\
\text { FES-I } \\
\text { TUG }\end{array}$ & $\begin{array}{l}\text { The Wii Fit group showed greater improvement in } \\
\text { obstacle crossing velocity, crossing stride length, } \\
\text { dynamic balance, SOT, TUG, FES-l, and PDQ39 } \\
\text { than the control group. Wii Fit training also resulted } \\
\text { in greater improvement in movement velocity of } \\
\text { limits-of-stability test than Traditional Exercise training. }\end{array}$ \\
\hline $\begin{array}{l}\text { Pompeu et al, } 2014 \text { [35] } \\
\text { (Case series) }\end{array}$ & $\begin{array}{l}\mathrm{n}=4 \\
67 \text { years } \\
\text { Hoehn and Yahr stages } 2 \\
\text { and } 3\end{array}$ & BESTest & $\begin{array}{l}\text { There was an improvement of } 9.19 \% \text { in the BESTest } \\
\text { score. This improvement may be related to the motor } \\
\text { and cognitive demands of the games. }\end{array}$ \\
\hline $\begin{array}{l}\text { Lee, Lee and Song, } \\
2015 \text { [29] (Randomized } \\
\text { controlled trial) }\end{array}$ & $\begin{array}{l}n=20 \\
68 \text { years } \\
\text { Experimental group }(n=10) \\
\text { Control group }(n=10)\end{array}$ & $\begin{array}{l}\text { BBS } \\
\text { Modified Barthel Index } \\
\text { Beck Depression Inventory }\end{array}$ & $\begin{array}{l}\text { There was significantly difference between before and } \\
\text { after treatment in the experimental group ( } 46.0 \pm 1.3 \\
\text { to } 48.1 \pm 3.0 ; p<0.05) \text { and significantly differed } \\
\text { between the experimental and control group in the } \\
\text { balance }(p<0.05) \text {, activities of daily living, and } \\
\text { depressive disorder status. Virtual reality dance exercise } \\
\text { has a positive effect on balance, activities of daily living, } \\
\text { and depressive disorder status of PD patients. }\end{array}$ \\
\hline Negrini et al, 2016 [31] & $\begin{array}{l}n=27 \\
66 \text { years }\end{array}$ & $\begin{array}{l}\text { BBS } \\
\text { POMA } \\
\text { FRT }\end{array}$ & $\begin{array}{l}\text { The results revealed significant differences for the } \\
\text { low dose group and for the high dose group (all, } \\
p<0.02 \text { ) for BBS and FRT, but not significant } \\
\text { difference was identified in POMA (all, } p<0.2) \\
\text { for the high dose group. There was no significant } \\
\text { difference between the groups ( } p>0.05 \text { ). }\end{array}$ \\
\hline
\end{tabular}

Note: Abbreviations: TUG, Timed up and go; BBS, Berg Balance scale; GDS, Geriatric Depression Scale; STST, Sit-to-Stand test; POMA, Tinetti Performance Oriented Mobility Assessment; CBM, Community Balance and Mobility assessment; ABC, Activities-specific Balance and Confidence scale; UPDRS, Unified Parkinson's Disease Rating Scale; UPDRS-II, Section II of the Unified Parkinson's Disease Rating Scale; DGI, Dynamic Gait Index; BESTest, Balance Evaluation Systems Test; SOT, sensory organization test; PDQ39, Parkinson's Disease Questionnaire; FES-I, fall efficacy scale; FRT: Falls risk test. 


\section{Discussion}

This systematic review has shown that there are not sufficient evidence to ensure the effectiveness and support of the inclusion of the treatment with NW to improve balance in adults with PD. However, the results of some studies suggest that the treatment with NW can be an alternative therapy to provide improvements in static, dynamic and functional balance aspects. Moreover, mobility in older adults suffering from PD can be improved in low or moderate level (stage 1-3 on the Hoehn and Yahr staging scale).

The results found was the effect of motor training combined with drug treatment. All patients followed their normal medication regimen during functional evaluation and exercise program were performed during the ON phase.

The Zettergren et al. [32] case study was the first that has studied the effects of NW in postural balance of one elderly patient suffering with PD. The NW was used two times per week for a total of eight weeks. Three balance game exercises were chosen: Penguin Slide, Table Tilt, and Balance Bubble. It was performed for 40-60 minutes per session, and the patient improved in the TUG by $34 \%$ and on the BBS by $25 \%$ [32].

As previously noted and using the same mobility outcome measure, Herz et al. [23] found significant improvements in TUG, after twenty elderly adults suffering from PD were trained with NW. In the same way, Loureiro et al. [33] showed statistically significant improvements comparing the initial and the final BBS assessments, even when the TUG has not improved [33].

In addition, Mhatre et al. [34] have shown significantly improvements in dynamic and static balance, according to the BBS test, in 10 patients diagnosed with PD that were trained with NW for 8 weeks. A second measure of balance, Dynamic Gait Index, also improved after training. Static balance, as measured by the Sharpened Romberg Test, indicated signs of improvement too. However, this was below the threshold of statistical significance. The authors also checked for differences in objective, quantifiable Wii Fit tests related to centre of pressure, and most of these tests indicated improvement in balance [34]. A similar study has also found improvements in BBS after training with NW sport games six elderly diagnosed with PD [30].
Esculier et al. [25] innovated comparing the balance results of elderly adults suffering from PD with health controls after performing a specific home-based training programme of approximately 40 minutes for 3 times per week during 6 weeks. All subjects have demonstrated an improvement in most of the static, dynamic and functional balance aspects. Increased one-leg stance duration in all participants indicated static balance improvements. Although the study results suggest that NW training should promote more balance improvements in elderly people with PD comparing with health controls. In this case, the visual feedback using NW even performed at home can be a therapeutic option to improve static and dynamic balance of people with PD. However, balance training interventions may require continuous feedback and postural adjustments by the physiotherapist, which cannot be easily replicated in the home setting without supervision [34].

Another study [26] has also used a home-based training with NW and the participants were motivated by a physiotherapist call every week to ensure that all patients performed training regularly and correctly. All individuals demonstrated an improvement in dynamic and functional balance aspects. A clear improvement of the BBS scores was also achieved after six weeks of NW training. Statistically differences were also noticed between the Tinnet's Performance Oriented Mobility Assessment scores obtained before the study and after six weeks of training [26]. The improvement in the BBS, Tinnet's Performance Oriented Mobility Assessment and TUG provide indications of increased balance and functional mobility of patients with PD.

A randomized clinical trial [20], have compared the effect of NW motor cognitive training versus balance exercise therapy on balance of elderly adults suffering from PD. The results showed that PD patients were able to improve their performance in three groups of games. The Wii-based motor and cognitive training improved the balance of the participants and this was maintained for 60 days after the end of training. The results also showed similar improvement between the participants performed by balance exercise therapy. No group has improved balance in the dual task, probably because the evidence that patients with PD have limited scope to improve their automatic control and attention management [37]. 
Unlike previous studies, a recent pilot study has used the BESTest to evaluate the balance of elderly adults with PD before and after NW training [35]. In this case, each participant was instructed by a physiotherapist about the rules and objectives of each game, only in the first session. Although the four participants were allowed to freely practice each game, they showed improvement in balance and gait after intervention.

A recent randomized controlled trial [29] innovated training of elderly diagnosed with PD with NW dance games. Twenty participants received 30 minutes of neurodevelopment treatment and 15 minutes of functional electrical stimulation, five times per week for six weeks. The experimental group participated in an additional 30 minutes of NW dance exercise. Balance assessed using the BBS had significantly improved in the experimental group, while the control group showed no significant improvement [29]. Compared to the control group, balance of the experimental group was significantly enhanced. The experimental group received 30 more minutes of treatment per session comparing to control group. This difference in training time may have interfered on the results.

A single-blinded, stratified, randomized controlled trial [36] has compared patients treated with NW exercises, conventional therapy and a control group. The experimental groups exhibited significant improvements in movement velocity and sensory organization test compared with the control group after training and at the 1-month follow-up. Moreover, the NW group exhibited greater improvement in movement velocity than conventional group. Also in TUG results, both experimental groups showed significant improvement compared with the control group after training and at follow-up. However, in TUG results no significant differences were found between the NW and conventional group. Perhaps a fourth group could clarify whether the combination of conventional exercises and NW training can promote better results.

According to Liao et al. [36], the virtual reality-based Wii Fit exercise was more effective than traditional exercise on improving mobility and balance control [36]. Maybe it has happened because virtual reality is a form of external feedback provided during training in auditory and visual feedback. The participants were able to make corrections according to this feedback to enhance their motor performance. Some of NW gaming programs require either attention or problem-solving ability probably activating cognitive pathway networks and consolidating the learning effect [38]. The observation of the virtual performance on the screen may facilitate the participation of mirror neurons, helping to make connections in the neural network that enhance learning and motor performance [39].

In Negrini et al. [31] protocol, 10 sessions was needed to reach a strong and significant treatment improvement. They evaluated the effectiveness of 10 vs. 15 sessions of NW Fit for patients with PD balance recovery. The patients undergoing the 10 and 15 sessions have demonstrated significantly improvement on the balance in the same way $(p<0.05)$.

\section{The limitations}

It is true that the methodological quality of the studies about the effects of NW training on elderly adults with PD has been improving since 2011. However, most studies did not include a control group and had small samples, which may limit the statistical analysis and generalization of the results. The short intervention period, the absence of follow-up evaluation, the subjective outcome measures should also be considered as other scientific limitations.

\section{Conclusion}

The chronic and degenerative nature of PD generates the necessity of a long-term rehabilitation programme. Repetitive exercises tend to become monotonous and it can induce an adverse effect on the adherence of the patient to the treatment. Thus, NW games could be used as a new tool in association with physical therapy in order to improve motivation, and consequently adherence, of patients in the long rehabilitation process. This will contribute to functional improvement and prevention of negative consequences of immobility. However, nobody has studied the influence of NW games on the motivation of people suffering from PD and adherence to treatment.

Although the NW exercises are limited for a group of elderly diagnosed with PD, this technological tool is inexpensive, readily available, and well tolerated by 
an ageing population of patients with PD. They have proved to be promising tools for the rehabilitation of lower limb function, especially for balance. In addition, the training with the NW performed over an unstable surface was safe and it did not cause adverse events and feasible.

The NW gaming system can be an effective treatment modality for patients with PD. However, further studies with larger numbers of patients are needed for better analysis of the results. Future research and a larger randomized controlled clinical trial assessing training variables are necessary to optimize this kind of exercise recommendations.

\section{References}

1. Health statistics and health information systems. World Health Organization. 2012.

2. Brasil. IBGE. Síntese de Indicadores Sociais: Uma análise das condições de vida da população brasileira. Rio de Janeiro; 2014.

3. Chaudhuri KR, Schapira AH. Non-motor symptoms of Parkinson's disease: dopaminergic pathophysiology and treatment. Lancet Neurol. 2009;8(5):464-74.

4. Wirdefeldt K, Adami HO, Cole P, Trichopoulos D, Mandel J. Epidemiology and etiology of Parkinson's disease: a review of the evidence. Eur J Epidemiol. 2011;26(Suppl 1):51-8.

5. Hornykiewicz 0 . The discovery of dopamine deficiency in the parkinsonian brain. J Neural Transm Suppl. 2006;(70):9-15.

6. Gelb DJ, Oliver E, Gilman S. Diagnostic criteria for Parkinson disease. Arch Neurol. 1999;56(1):33-9.

7. Canning CG, Ada L, Johnson JJ, McWhirter S. Walking capacity in mild to moderate Parkinson's disease. Arch Phys Med Rehabil. 2006;87(3):371-5.

8. Light KE, Behrman AL, Thigpen M, Triggs WJ. The 2-minute walk test: a tool for evaluating walking endurance in clients with Parkinson's disease. Neurol Rep. 1997;21(4):136-9.

9. Lang AE, Lozano AM. Parkinson's disease. First of two parts. N Engl J Med. 1998;339(15):1044-53.
10. Toth MJ, Fishman PS, Poehlman ET. Free-living daily energy expenditure in patients with Parkinson's disease. Neurology. 1997;48(1):88-91.

11. Kwakkel G, de Goede CJ, van Wegen EE. Impact of physical therapy for Parkinson's disease: a critical review of the literature. Parkinsonism Relat Disord. 2007;13(Suppl 3):478-87.

12. van der Kolk NM, King LA. Effects of exercise on mobility in people with Parkinson's disease. Mov Disord. 2013;28(11):1587-96.

13. Ganz DA, Bao Y, Shekelle PG, Rubenstein LZ. Will my patient fall? JAMA. 2007;297(1):77-86.

14. Rudzińska M, Bukowczan S, Stożek J, Zajdel K, Mirek E, Chwała W, et al. The incidence and risk factors of falls in Parkinson disease: prospective study. Neurol Neurochir Pol. 2013;47(5):431-7.

15. Michałowska M, Fiszer U, Krygowska-Wajs A, Owczarek K. Falls in Parkinson's disease. Causes and impact on patients' quality of life. Funct Neurol. 2005;20(4):163-8.

16. Gil-Gómez JA, Lloréns $\mathrm{R}$, Alcañiz $\mathrm{M}$, Colomer C. Effectiveness of a Wii balance board-based system (eBaViR) for balance rehabilitation: a pilot randomized clinical trial in patients with acquired brain injury. J Neuroeng Rehabil. 2011;8:30.

17. Moher D, Shamseer L, Clarke M, Ghersi D, Liberati A, Petticrew M, et al. Preferred reporting items for systematic review and meta-analysis protocols (PRISMA-P). 2015 statement. Syst Rev. 2015;4:1.

18. Verhagen AP, de Vet HC, de Bie RA, Kessels AG, Boers M, Bouter LM, et al. The Delphi list: a criteria list for quality assessment of randomized clinical trials for conducting systematic reviews developed by Delphi consensus. J Clin Epidemiol. 1998;51(12):1235-41.

19. The Cochrane Collaboration. Cochrane Handbook for Systematic Reviews of Interventions Version 5.1.0. 2014 [cited 2014 Aug 2]. Available from: http:// handbook.cochrane.org/.

20. Pompeu JE, Mendes FA, Silva KG, Lobo AM, Oliveira Tde $\mathrm{P}$, Zomignani AP, et al. Effect of Nintendo Wii ${ }^{\mathrm{TM}}$-based motor and cognitive training on activities of daily living in patients with Parkinson's disease: a randomised clinical trial. Physiotherapy. 2012;98(3):196-204. 
21. Liao YY, Yang YR, Cheng SJ, Wu YR, Fuh JL, Wang RY. Virtual Reality-Based Training to Improve ObstacleCrossing Performance and Dynamic Balance in Patients With Parkinson's Disease. Neurorehabil Neural Repair. 2015;29(7):658-67.

22. Lee NY, Lee DK, Song HS. Effect of virtual reality dance exercise on the balance, activities of daily living, and depressive disorder status of Parkinson's disease patients. J Phys Ther Sci. 2015;27(1):145-7.

23. Herz NB, Mehta SH, Sethi KD, Jackson P, Hall P, Morgan JC. Nintendo Wii rehabilitation ("Wii-hab") provides benefits in Parkinson's disease. Parkinsonism Relat Disord. 2013;19(11):1039-42.

24. Purves D, Augustine GJ, Fitzpatrick D, Hall WC, LaMantia AS, McNamara JO, et al. Neuroscience. 4th ed. Sunderland, MA: Sinauer Associates; 2008.

25. Esculier JF, Vaudrin J, Bériault P, Gagnon K, Tremblay LE. Home-based balance training programme using Wii Fit with balance board for Parkinsons's disease: a pilot study. J Rehabil Med. 2012;44(2):144-50.

26. Zalecki T, Gorecka-Mazur A, Pietraszko W, Surowka AD, Novak P, Moskala M, et al. Visual feedback training using WII Fit improves balance in Parkinson's disease. Folia Med Cracov. 2013;53(1):65-78.

27. Lacour M, Bernard-Demanze L, Dumitrescu M. Posture control, aging, and attention resources: models and posture-analysis methods. Neurophysiol Clin. 2008;38(6):411-21.

28. Yen $\mathrm{CY}$, Lin $\mathrm{KH}, \mathrm{Hu} \mathrm{MH}, \mathrm{Wu} \mathrm{RM}, \mathrm{Lu} \mathrm{TW}$, Lin $\mathrm{CH}$. Effects of virtual reality-augmented balance training on sensory organization and attentional demand for postural control in people with Parkinson disease: a randomized controlled trial. Phys Ther. 2011;91(6):862-74.

29. Lee NY, Lee DK, Song HS. Effect of virtual reality dance exercise on the balance, activities of daily living, and depressive disorder status of Parkinson's disease patients. J Phys Ther Sci. 2015;27(1):145-7.

30. Silva FD, Polese JC, Alvarenga LFC, Schuster RC. Efeitos da Wiireabilitação Na Mobilidade de Tronco de Indivíduos com Doença de Parkinson: Um Estudo Piloto. Rev Neurocienc. 2013;21(3):364-8.
31. Negrini S, Bissolotti L, Ferraris TA, Noro F, Bishop MD, Villafañe JH. Nintendo Wii Fit for Balance Rehabilitation in Patients with Parkinson's Disease: a compartive study. J Bodyw Mov Ther. 2017;21(1):117-23.

32. Zettergren K, Franca J, Antunes M, Lavallee C. The effects of Nintendo Wii Fit training on gait speed, balance, functional mobility and depression in one person with Parkinson's disease. ATI. 2011;5(2):38-44.

33. Loureiro APC, Ribas CG, Zotz TGG, Chen R, Ribas F. Feasibility of virtual therapy in rehabilitation of Parkinson's disease patients: pilot study. Fisioter. Mov. 2012;25(3):659-66.

34. Mhatre PV, Vilares I, Stibb SM, Albert MV, Pickering L, Marciniak CM, et al. Wii Fit balance board playing improves balance and gait in Parkinson disease. PM R. 2013;5(9):769-77.

35. Pompeu JE, Andrade G, Mendonça MS, Pompeu SMAA, Lange B. Safety, Feasibility and Effectiveness of Balance and Gait Training Using Nintendo Wii Fit Plus $^{\mathrm{TM}}$ on Unstable Surface in Patients with Parkinson's Disease: A Pilot Study. J Alzheimers Dis Parkinsonism. 2014;4(1):1-4.

36. Liao YY, Yang YR, Cheng SJ, Wu YR, Fuh JL, Wang RY. Virtual Reality-Based Training to Improve ObstacleCrossing Performance and Dynamic Balance in Patients With Parkinson's Disease. Neurorehabil Neural Repair. 2015;29(7):658-67.

37. Wu T,HallettM.Neuralcorrelates of dualtaskperformance in patients with Parkinson's disease. J Neurol Neurosurg Psychiatry 2008;79(7):760-6.

38. Mirelman A, Maidan I, Deutsch JE. Virtual reality and motor imagery: promising tools for assessment and therapy in Parkinson's disease. Mov Disord. 2013;28(11):1597-608.

39. Iacoboni M, Mazziotta JC. Mirror neuron system: basic findings and clinical applications. Ann Neurol. 2007;62(3):213-8.

Received on $07 / 12 / 2016$

Recebido em 12/07/2016

Approved on 06/21/2017 Aprovado em 21/06/2017 